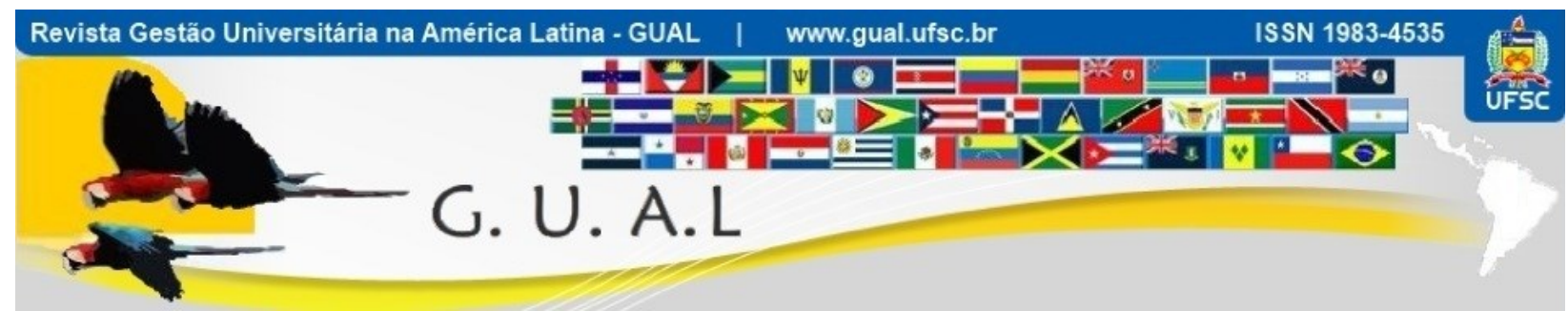

DOI: http://dx.doi.org/10.5007/1983-4535.2014v7n2p86

\title{
FATORES DE INFLUÊNCIA NA ESCOLHA DE UM CURSO DE PÓS-GRADUAÇÃO: UMA ANÁLISE DO MBA EM GESTÃO ESTRATÉGICA DE PESSOAS DA UFJF
}

\author{
INFLUENCE OF FACTORS IN CHOOSING A GRADUATE COURSE: AN \\ ANALYSIS OF MBA IN STRATEGIC MANAGEMENT PEOPLE OF UFJF
}

Patrícia de Rezende Martins, Especialista
Universidade Federal de Juiz de Fora - UFJF
patriciaderezendemartins@gmail.com
Victor Cláudio Paradela Ferreira, Doutor
Universidade Federal de Juiz de Fora - UFJF
victorclaudio@uol.com.br
Débora Vargas Ferreira Costa, Mestra
Universidade Federal de Juiz de Fora - UFJF
debora1@powermail.com.br

Recebido em 22/junho/2013

Aprovado em 19/abril/2014

Sistema de Avaliação: Double Blind Review

Esta obra está sob uma Licença Creative Commons Atribuição-Uso. 


\title{
RESUMO
}

Este artigo tem por objetivo identificar os fatores que motivam os alunos a se matricularem no MBA em Gestão Estratégica de Pessoas da Universidade Federal de Juiz de Fora. Como pano de fundo para o entendimento do problema investigado, o trabalho aborda algumas características da sociedade contemporânea, em especial aquelas ligadas ao perfil profissional demandado e à crescente competitividade. Outros temas estudados são a história e o desenvolvimento dos cursos de pós-graduação na modalidade MBA e as principais teorias sobre o comportamento do consumidor, no que tange à escolha de determinados produtos ou serviços. Foi realizada uma pesquisa de campo com uma amostra do tipo conglomerado, da qual participaram os alunos matriculados em 2012. O instrumento de coleta de dados foi um questionário com questões abertas e fechadas sobre o perfil dos participantes, seus interesses e expectativas determinantes da escolha do curso. $\mathrm{O}$ artigo apresenta as conclusões a que foi possível se chegar após a tabulação desses dados, destacando a preponderância do desejo de adquirir novos conhecimentos e maior capacitação profissional, como fatores indutores da matrícula em um MBA, e a tradição e qualidade de ensino como determinantes na escolha da instituição.

Palavras-Chave: Gestão educacional. Comportamento do consumidor. Master of Business Administration.

\begin{abstract}
This article aims to identify the factors that motivate students to enroll in the MBA in Strategic People Management at the Federal University of Juiz de Fora. As background for understanding the problem investigated, the paper discusses some features of contemporary society, especially those related to professional profile defendant and the increasing competitiveness. Other topics studied are the history and development of postgraduate courses in the MBA and the main mode theories of consumer behavior, with respect to the choice of certain products or services. We conducted a field study with a sample of conglomerate, attended by students enrolled in 2012. The data collection instrument was a questionnaire with open and closed questions about the profile of the participants, their interests and expectations determinants of choice of course. The article presents the conclusions that could be reached after the tabulation of these data, highlighting the preponderance of the desire to acquire new knowledge and higher professional training as factors that induce enrollment in an MBA, and the tradition and quality of education as determinants in the choice the institution.
\end{abstract}

Keywords: Education Management. Consumer behavior. Master of Business Administration. 


\section{INTRODUÇÃO}

Para uma compreensão melhor do tema aqui enfocado - os fatores que determinam a escolha de um curso de MBA - é interessante a apreciação da ambiência de trabalho contemporânea. Antigos paradigmas profissionais, que dominaram as organizações ao longo do último século, estão passando por uma profunda revisão, diante das novas características assumidas pela sociedade.

Taylor, um dos precursores da Escola Clássica da Administração, acreditava que o homem era simples e previsível, deveria ser vigiado, era incentivado exclusivamente por dinheiro e o treinamento era a única coisa necessária para garantir produtividade. Motta e Vasconcellos (2006) destacam que essa concepção do trabalhador foi chamada de Homo Economicus. Posteriormente, com o surgimento da Escola das Relações Humanas, o conceito foi modificado, e recebeu o nome de Homo Socialis, cujo comportamento não pode ser conceituado como simples e mecanicista, e o homem é condicionado pelo sistema social.

Porém, ainda de acordo com Motta e Vasconcellos (2006), essas teorias sobre o homem foram postas em cheque com as teorias motivacionais e de liderança. Abraham Maslow, ao estudar as necessidades humanas, conceituou o ser humano como Homo Complexus, capaz de manifestar necessidades ligadas ao ego, ao desenvolvimento pessoal, assim como à sua aprendizagem e à auto-realização. Tais estudos demonstraram que o indivíduo tem a necessidade de construir a sua identidade, ou seja, cada um tem objetivos e interesses diversos, e estes modificam ao longo dos tempos.

No contexto atual, novos desafios se impõem para as organizações. Tamanho é o nível de competição e tão significativas as dificuldades enfrentadas, que muitas empresas precisam preocupar-se mais com a sobrevivência do que propriamente com a expansão e obtenção de vantagens competitivas. Dentre outros fatores, essa situação advém da maior troca e acesso de informações, promovidas, principalmente, pelo fenômeno da globalização.

As transformações no modo como os negócios são realizados e projetados requerem das empresas, segundo Schaffer (2002), uma constante revisão nas práticas de treinamento dos colaboradores, executivos ou não. Não somente as empresas manifestam essa necessidade. As instituições de ensino representam outro tipo de organização que precisam manter-se atentas e, preferencialmente, antecipar-se às tendências. Essa necessidade se revela ainda mais importante nos cursos de pós-graduação voltados para a gestão organizacional, 
conhecidos como MBAs (Master of Business Administration), tendo em vista a grande expansão na oferta observada nos últimos anos, que tornou o setor bastante competitivo.

Tal expansão deriva da importância da obtenção de qualificação para a inserção no mercado de trabalho. Schaffer (2002) afirma que muitos recrutadores escolhem candidatos que estão cursando ou já possuem um MBA. Ou seja, existe um diferencial vantajoso para quem investe nesse tipo de curso, o que tem estimulado ao aumento nas matrículas no mesmo.

Percebendo as oportunidades oferecidas pela alta procura, muitas instituições de ensino estão investindo na oferta de MBAs. Nem sempre, porém, os cursos alcançam boa aceitação no mercado educacional. Enquanto algumas escolas de negócio possuem grande número de alunos, outras apresentam muitas vagas ociosas. A Universidade Federal de Juiz de Fora, objeto de estudo da pesquisa aqui apresentada, mantém, desde 1999 diversos cursos nessa modalidade, dentre eles o focado em Gestão de Pessoas, no qual se concentra a atenção deste trabalho, cuja primeira turma foi aberta em 2006. Para manter um bom conceito entre os públicos atendidos, é fundamental conhecer quais os principais motivos que os levam a buscar a pós-graduação e a escolher o curso no qual vai se matricular. Somente com a correta identificação das expectativas é que se pode oferecer aos públicos atendidos por qualquer organização produtos e serviços adequados.

Com base nessas constatações, o presente artigo busca identificar quais fatores motivaram os alunos do MBA de Gestão Estratégica de Pessoas da UFJF, da turma de 2012, a escolherem esse curso.

A próxima seção expõe a metodologia utilizada para investigar a questão apresentada.

\section{METODOLOGIA}

A abordagem adotada para o tratamento e discussão dos dados obtidos na pesquisa de campo, foi predominantemente qualitativa, privilegiando a análise das opiniões apresentadas, pelos sujeitos participantes da pesquisa, nas entrevistas realizadas na etapa de coleta de dados (CERVO E BERVIAN, 2007).

Corroborando com a concepção de pesquisa qualitativa, Gaskell (2004, p. 91), aponta que este tipo de pesquisa procura mapear e investigar o mundo dos entrevistados com a intenção de "compreender melhor as crenças, atitudes, valores e motivações em relação ao comportamento humano dentro de contextos sociais específicos". 
O universo pesquisado está constituído pelos alunos do curso em foco, em suas diversas edições. Trabalhou-se especificamente com estudantes da turma de 2012, adotandose, em consequência, uma amostragem do tipo conglomerado, que se caracteriza por pressupor a divisão dos itens de uma população em subgrupos heterogêneos, representativos da população total (COSTA, 2011). O trabalho se caracteriza, de acordo com Gil (2009), como uma pesquisa do tipo descritivo-exploratória. A classificação como descritiva é decorrente de que se pretendeu constatar o fenômeno investigado (motivos da escolha do curso estudado), sem a intenção de buscar explicações para as motivações identificadas. É exploratória, visto que não foram encontradas pesquisas similares disponíveis para consulta, sendo necessária a investigação a partir unicamente de dados colhidos diretamente no campo.

A pesquisa se configura também como um estudo de caso, que se caracteriza por proporcionar uma descrição global de um problema ou identificar características que o influenciam, ou seja, não possui intenção de delinear ou descrever um conhecimento detalhado dos fatores de uma realidade (GIL, 2009). Como a pesquisa utilizou referências eletrônicas, classifica-se, de acordo com Vergara (2010), como uma pesquisa telematizada.

A pesquisa de campo realizada consistiu na aplicação de um questionário nos alunos da turma escolhida, contendo questões fechadas complementadas com duas perguntas abertas. A aplicação foi procedida pela pesquisadora, que, após explicar o objetivo da pesquisa, distribuiu os questionários e realçou que não era necessária a identificação, sendo as respostas inseridas aleatoriamente em uma pasta. Com isso, procurou-se preservar a confidencialidade das respostas, favorecendo a maior sinceridade nas manifestações. Outras informações sobre o questionário encontram-se na seção que apresenta os resultados obtidos no campo.

Antes da exposição do estudo de caso, a próxima seção apresenta uma revisão bibliográfica com análise de artigos, capítulos de livros e pesquisas já consolidadas.

\section{A HISTÓRIA DOS CURSOS DE MBA E SUA ATUAL IMPORTÂNCIA NO MERCADO DE TRABALHO}

Em 1908, surgiram os primeiros cursos de MBA em escolas de negócios norteamericanas. Entre os anos de 1960 e 1970, houve um crescimento desse tipo de curso e a exportação para outros continentes (Castro, 1981). O Plano Marshall e o crescimento das multinacionais norte-americanas fomentaram a disseminação e o crescimento dos MBAs na Europa. Cambridge e Oxford, renomadas universidades, criaram escolas de negócio e desenvolveram, no início dos anos 1990, cursos de MBA (Warde, 2000). 


\section{FATORES DE INFLUÊNCIA NA ESCOLHA DE UM CURSO DE PÓS-GRADUAÇÃO: UMA ANÁLISE DO \\ MBA EM GESTÃO ESTRATÉGICA DE PESSOAS DA UFJF \\ DOI: http://dx.doi.org/10.5007/1983-4535.2014v7n2p86}

De acordo com Martins (1989), em outros países, como a Inglaterra e os Estados Unidos, o processo de afirmação da Administração estava atrelado ao crescimento da industrialização. No Brasil, porém, esse processo ocorreu quando o país já experimentava o desenvolvimento de alguns setores industriais e de serviços na década de 1940.

Conforme destaca Barboza (2010), após a abertura de mercado a produtos e serviços estrangeiros, iniciada no governo Collor (1990/1992), as indústrias estavam mais competitivas e necessitavam capacitar seus funcionários. Diante desse cenário, houve expansão e a consolidação dos cursos de pós-graduação.

Hoje, segundo Barboza (2010), o diploma de graduação para o mercado de trabalho já não é considerado como diferencial e sozinho não é capaz de agregar valor ao currículo ao candidato que busca colocação no mercado de trabalho.

As mudanças econômicas, sociais, políticas, culturais e tecnológicas trazidas pela globalização e a ascensão de novos processos produtivos trouxeram, de acordo com Fogaça (1998), uma nova concepção - a inter-relação entre a educação geral e a educação profissional. Nessa concepção, Dowbor (1996), defende que não é mais possível negar a necessidade de sinergia entre empresas, organizações educacionais e a comunidade.

Conforme destacam Gílio (2000) e Karlof (1999), a globalização também trouxe algumas exigências para o perfil do profissional, que agora deve conseguir lidar com diversos fatores simultaneamente. Concomitantemente com essas ideias, existe um movimento para reestruturação das organizações, exigindo cada vez mais esse perfil do trabalhador, que está embasado em três grupos de habilidades: a) as que são alcançadas com a educação formal cognitivas; b) técnicas; c) comportamentais (atitudes).

Em cada uma dessas dimensões, podem ser apontadas importantes habilidades que precisam ser desenvolvidas, conforme demonstrado na figura 1. 


\begin{tabular}{|c|c|c|c|}
\hline $\begin{array}{l}\text { Área } \\
\text { Humana }\end{array}$ & $\begin{array}{l}\text { HABILIDADES } \\
\text { COGNITIVAS } \\
\text { Saber argumentar, ter } \\
\text { visão ampla resolver } \\
\text { problemas. }\end{array}$ & $\begin{array}{c}\text { HABILIDADES TÉCNICAS } \\
\text { Dominar outro idioma, conhecer informática, } \\
\text { fazer design gráfico, trab. imagem } \\
\text { institucional, trab. Marketing, planejar impacto } \\
\text { ambiental em empresas, ter experiência. }\end{array}$ & $\begin{array}{l}\text { HABILIDADES } \\
\text { COMPORTAMENTAIS } \\
\text { Ser ético, ser versátil, ser } \\
\text { multiprofissional }\end{array}$ \\
\hline $\begin{array}{l}\text { Área } \\
\text { Saúde }\end{array}$ & $\begin{array}{l}\text { HABILIDADES } \\
\text { COGNITIVAS } \\
\text { Resolver problemas } \\
\text { comunicar-se. }\end{array}$ & $\begin{array}{c}\text { HABILIDADES TÉCNICAS } \\
\text { Dominar outro idioma, conhecer } \\
\text { informática, atuar em ecoturismo, atuar em } \\
\text { estética e redução de dores. }\end{array}$ & $\begin{array}{c}\text { HABILIDADES } \\
\text { COMPORTAMENTAIS } \\
\text { Trabalhar em equipe }\end{array}$ \\
\hline $\begin{array}{l}\text { Área } \\
\text { Exatas }\end{array}$ & $\begin{array}{l}\text { HABILIDADES } \\
\text { COGNITIVAS } \\
\text { Resolver problemas } \\
\text { comunicar-se }\end{array}$ & $\begin{array}{c}\text { HABILIDADES TÉCNICAS } \\
\text { Dominar outro idioma, conhecer } \\
\text { informática, atuar em ecoturismo, atuar em } \\
\text { estética e redução de dores. }\end{array}$ & $\begin{array}{c}\text { HABILIDADES } \\
\text { COMPORTAMENTAIS } \\
\text { Trabalhar em equipe }\end{array}$ \\
\hline
\end{tabular}

Figura 1 Exemplos de habilidades por áreas de atuação Fonte: Gondim (2002, p.305)

Nota-se, portanto, que há uma variada gama de habilidades que se revelam importantes. A qualificação profissional revela-se ainda mais relevante, em consequência, favorecendo a expansão da demanda por MBAs.

De acordo com Bruno (1996), os recrutadores estão cada vez mais com dificuldades para encontrar profissionais habilitados a preencherem as vagas ofertadas. A crescente proporção candidato/vaga evidencia também a dificuldade de muitos em preencher as exigências do mercado.

$\mathrm{Na}$ concepção de Oliveira (2001), os indivíduos, o Estado e as empresas viram a educação como um excelente investimento, pois seria assim possível formar mão de obra qualificada. O Estado e os indivíduos acreditavam numa melhora da qualidade de vida, resultante do aumento de renda.

Conhecidas algumas abordagens que respaldam a importância dos MBAs, a próxima seção apresenta um estudo sobre os fatores motivacionais dos consumidores.

\section{A MOTIVAÇÃO DOS CONSUMIDORES}

Clientes são pessoas que possuem necessidades e desejos que serão satisfeitos pela escolha que fará de produtos e serviços. Cada pessoa, porém, é diferente da outra e responde diferentemente os estímulos do marketing. Esse comportamento individualizado é resultante da combinação de diversos fatores inerentes ao ser humano, como, por exemplo, formação, cultura e comportamento (Kotler, 1998). 
Para Kotler (1998), além das reações individuais das pessoas resultantes dos estímulos de marketing atrelados ao preço, produto, ponto de venda e a comunicação, existem outros fatores, como, por exemplo, os econômicos, políticos, culturais e tecnológicos. Esses fatores descritos combinados com as características de personalidade resultam no processo de decisão da compra que irá avaliar diversos fatores e características dos produtos e serviços ofertados, conforme demonstrado a seguir na figura 2.

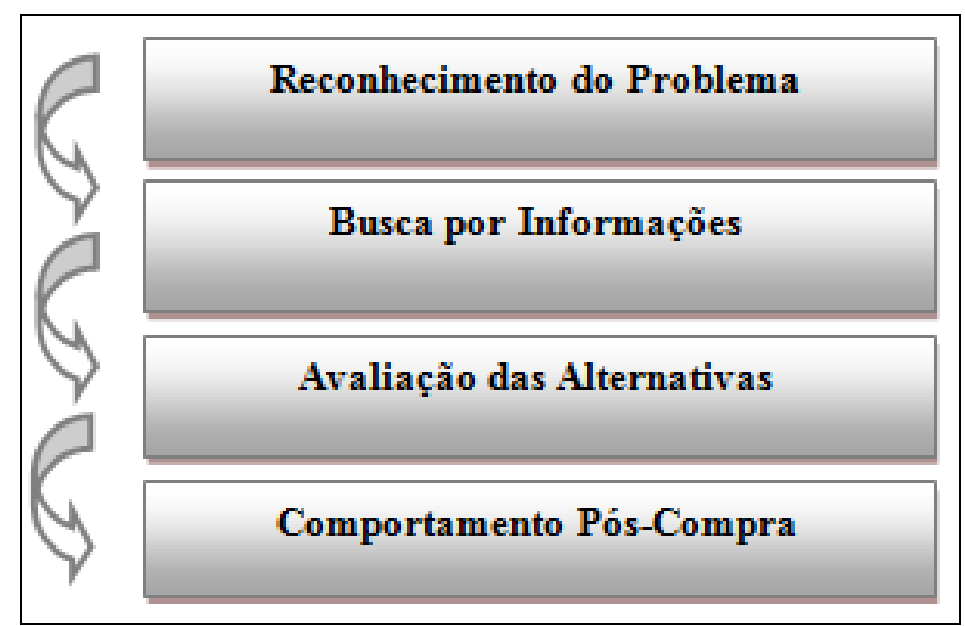

Figura 2 Etapas do processo de compra Fonte: Kotler (2001, p.83)

De acordo com Churchill (2005, p. 154-156), são consideradas como influências sociais a cultura e a subcultura. A cultura seria um "complexo de valores e comportamentos aprendidos que são compartilhados por uma sociedade e destinam-se a aumentar sua probabilidade de sobrevivência". A subcultura seria um "segmento dentro de uma cultura que compartilha valores e padrões de comportamentos distintos da cultura geral". Esses elementos exercem influência direta e indireta na concepção do comportamento. As pessoas são influenciadas também por sua classe social ("grupo de pessoas que têm valores e prestígios similares"), grupos de referência ("pessoas que influenciam os pensamentos, sentimentos e ações dos consumidores”) e pela família.

Essas influências estão demonstradas na figura 3. 


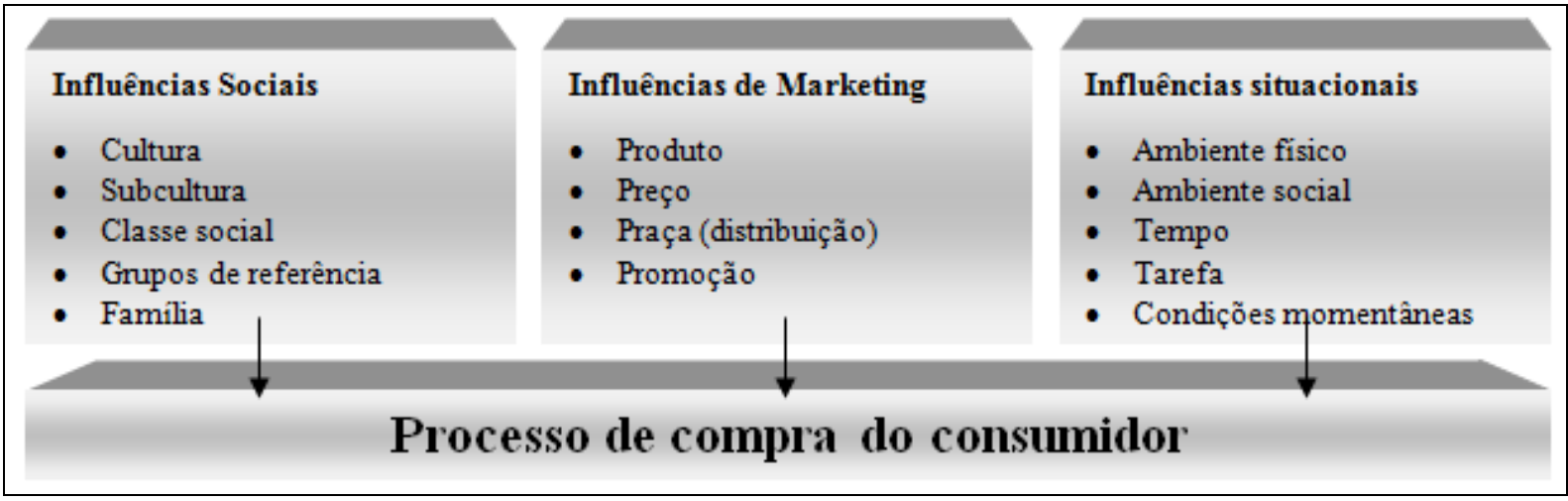

Figura 3 Influências no processo de compra Fonte: Churchill (2005, p.153)

As estratégias de marketing citadas anteriormente são compostas pelo produto, preço, praça e promoção. O produto pode influenciar a avaliação deste pelo consumidor e sua capacidade de proporcionar valor. A estratégia de preço pode determinar a seleção de um produto que aumente ou diminua o custo total da compra. A praça pode influenciar a seleção conforme a disponibilidade do produto. Por fim, a promoção pode atrair novos consumidores e divulgar a marca (Kotler, 2009). As estratégias de marketing podem ser melhor visualizadas na figura a seguir.

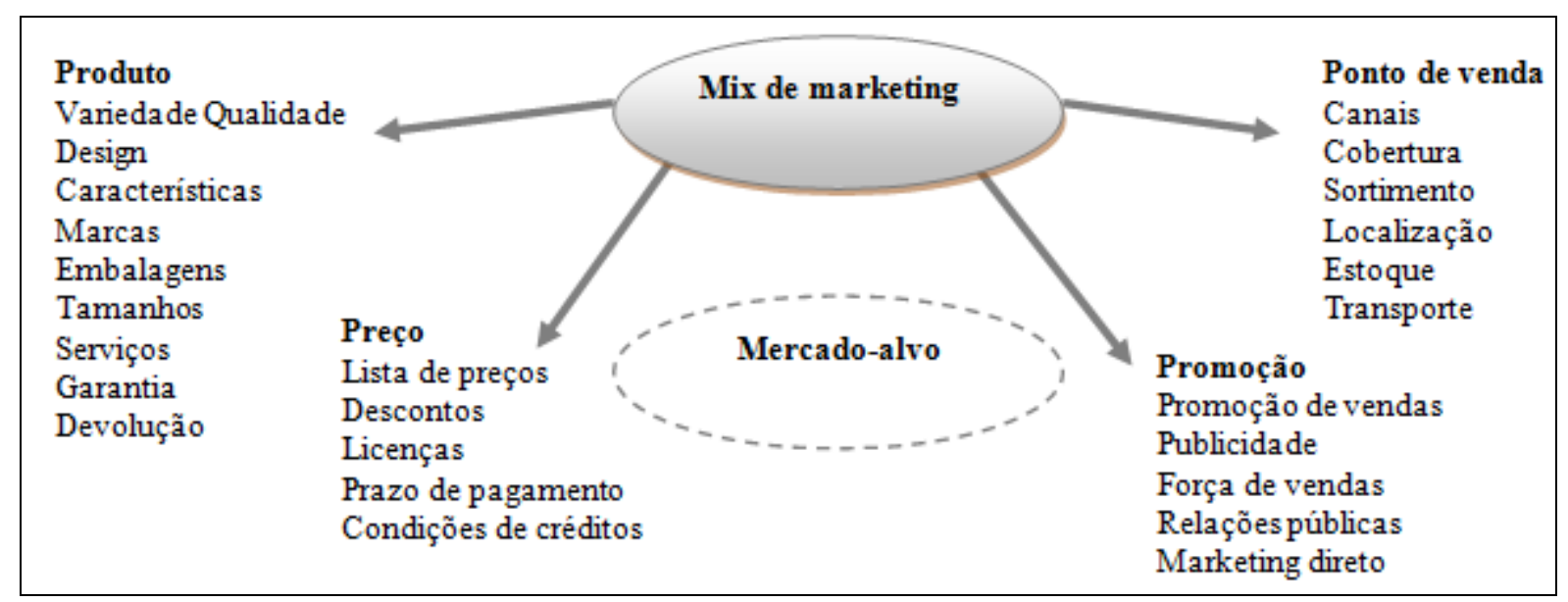

Figura 4 Os 4 Ps do marketing Fonte: Kotler (2009, p.97)

A figura 4 exemplifica todos os compostos da influência do marketing na estratégia de um produto ou serviço. Um bom direcionamento em todas as vertentes (produto, preço, ponto de venda e promoção), faz com que a organização consiga atingir de forma eficaz seu público-alvo. 
Conforme Kotler (2009), os consumidores iniciam o processo de compra ao identificarem uma necessidade, e posteriormente, buscando mais informações sobre o produto e alternativas em relação a marcas. Após essas considerações, avaliam as alternativas e tomam uma decisão de compra. Em seguida, avaliam a compra. Nessa etapa procuram perceber se o valor recebido pela aquisição do produto foi menor, igual ou superior à expectativa.

De acordo com Churchill (2005), existem alguns tipos de tomada de decisão. São eles: a) rotineira - envolvem poucas atividades de pesquisa; b) limitada - possui um nível moderado de pesquisa e compra; c) extensiva - nível considerado de pesquisa, geralmente quando o produto é importante, o preço é alto, é complexo ou pouco conhecido e quando há muitas marcas. O quadro 1 demonstra quais as características de cada tipo de decisão.

\begin{tabular}{|c|c|c|c|c|}
\hline $\begin{array}{c}\text { Tipo de } \\
\text { decisão }\end{array}$ & $\begin{array}{c}\text { Envolvimento do } \\
\text { consumidor }\end{array}$ & $\begin{array}{c}\text { Características do conjunto } \\
\text { considerado }\end{array}$ & $\begin{array}{c}\text { Fontes de informação } \\
\text { consultadas }\end{array}$ & $\begin{array}{c}\text { Tempo } \\
\text { investido }\end{array}$ \\
\hline Rotineira & Baixo & $\begin{array}{c}\text { Poucas opções de marcas, } \\
\text { vendedores e características de } \\
\text { produtos avaliados }\end{array}$ & $\begin{array}{c}\text { O mínimo } \\
\text { possível }\end{array}$ \\
\hline Limitada & Moderado & $\begin{array}{c}\text { Várias marcas, vendedores e } \\
\text { características de produtos } \\
\text { avaliados }\end{array}$ & $\begin{array}{c}\text { Internas e algumas } \\
\text { externas }\end{array}$ & Pouco \\
\hline Extensiva & Alto & $\begin{array}{c}\text { Muitas marcas, vendedores e } \\
\text { características de produtos } \\
\text { avaliados }\end{array}$ & $\begin{array}{c}\text { Algumas internas e } \\
\text { muitas externas }\end{array}$ & Muito \\
\hline
\end{tabular}

Quadro 1 Tipos de decisão

Fonte: Churchill (2005, p.152)

Os responsáveis pelo delineamento das características de um produto ou serviço devem considerar o perfil dos consumidores de seus produtos e analisar o que pode ter influenciado sua decisão de comprar a partir das etapas estudadas acima. Após estas considerações, é preciso analisar o que pode ajudar a influenciar novos consumidores e como atraí-los utilizando as ferramentas estratégicas do marketing.

A partir das considerações aqui destacadas, buscou-se aplicar os princípios estudados na identificação do perfil dos alunos e da motivação que os levou a matricular-se no MBA em foco. A próxima seção apresenta os resultados obtidos na pesquisa de campo realizada.

\section{RESULTADOS OBTIDOS NO CAMPO}

Em 2012, quando foi realizada a pesquisa, os cursos oferecidos pela Faculdade de Administração e Ciências Contábeis (FACC/UFJF) foram: Gestão Estratégica de Pessoas, Marketing e Negócios, Projetos, Finanças e Negócios e Empreendimentos, alcançaram 302 
matrículas. No MBA em estudo, a turma está constituída por 38 alunos, sendo o curso mais procurado de 2012. Desde o seu início (2006) e até 2010 (os dados de 2011 encontravam-se em processo de análise no momento de fechamento deste relatório), 146 pessoas já concluíram esse curso. Conforme destacado na seção que apresentou a metodologia, foi aplicado um questionário nos alunos da turma atual do MBA Gestão Estratégica de Pessoas. Esse instrumento contou com seis questões de múltipla escolha, duas questões para ordenar as respostas e outras duas questões dissertativas. Dos 38 alunos que compõem a turma, 29 responderam, pois os demais não estiveram presentes no momento da aplicação.

A distribuição quanto ao gênero está demonstrada a seguir.



Figura 5 Distribuição de respondentes por gênero Fonte: Os autores

Verifica-se que a maioria dos respondentes é do sexo feminino, o que reflete bem o perfil da turma e revela-se uma característica comum em cursos na área de gestão de pessoas.

A distribuição da faixa etária dos participantes está descrita a seguir.

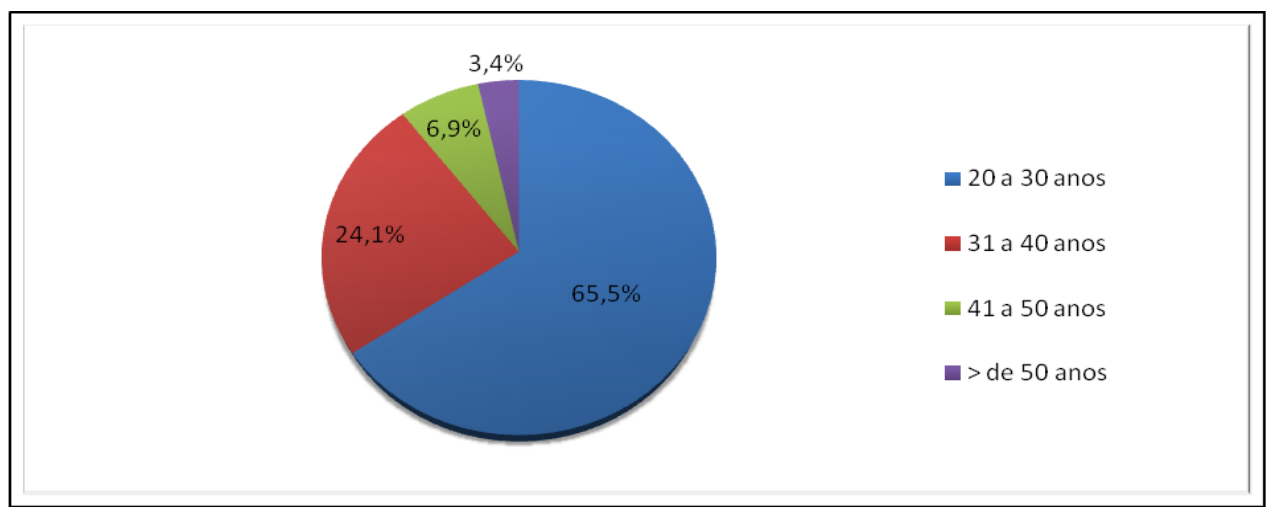

Figura 6 Faixa etária dos participantes Fonte: Os autores 
Constata-se que, de modo geral, os estudantes dessa turma são jovens, estando a maioria entre 20 e 30 anos. Essa característica explica o tempo de atuação profissional que é revelado na figura 11 .

Nem todos os alunos atuam na área de gestão de pessoas, conforme a figura 7.

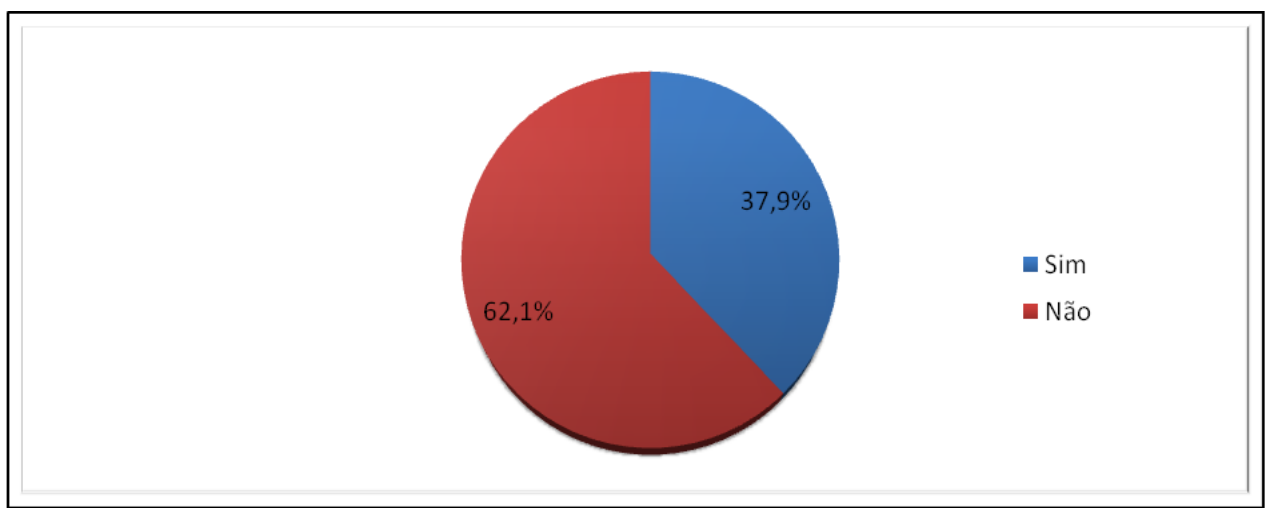

Figura 7 Alunos que trabalham na área de gestão de pessoas Fonte: Os autores

É possível notar que a maior parte $(62,1 \%)$ não trabalha atualmente na área de gestão de pessoas. O curso parece atrair também profissionais que necessitam de uma pós-graduação para ascender na carreira da organização em que trabalham, sem a necessidade de uma formação específica. Assim, há alunos que atuam em bancos e outros que são empresários, conforme mostra a figura 9. Para esses, o curso de gestão de pessoas torna-se uma opção interessante à medida que os prepara para o gerenciamento de suas equipes de liderados.

A figura 8 revela os cargos dos alunos que trabalham na área de gestão de pessoas.

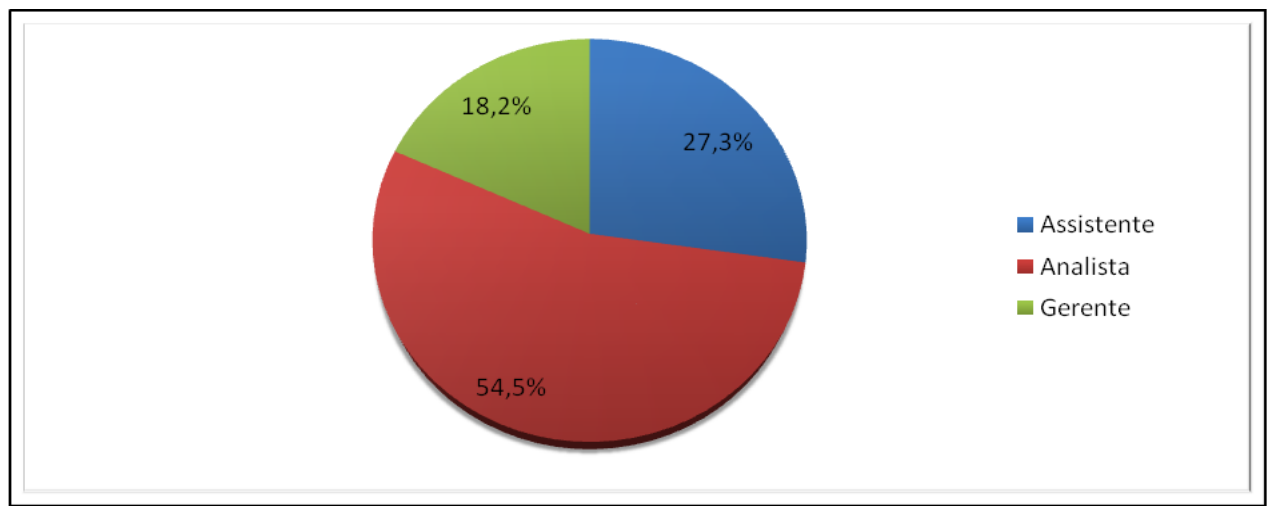

Figura 8 Nível profissional dos que trabalham em gestão de pessoas Fonte: Os autores 
A figura 8 demonstra que a maior parte $(54,5 \%)$ dos respondentes que atua com gestão de pessoas está no início da carreira profissional. O curso parece atrair, portanto, pessoas que buscam ascensão na escala hierárquica ou que buscam aprimoramento de seus conhecimentos.

A figura 9 apresenta os cargos dos alunos que não trabalham com gestão de pessoas.

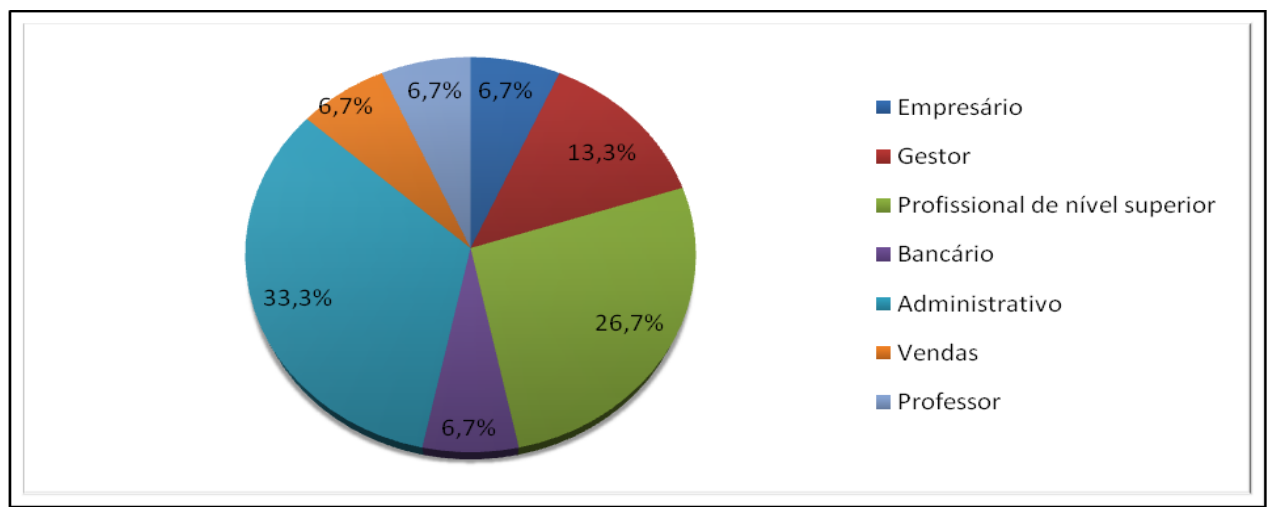

Figura 9 Funções desempenhadas pelos que não trabalham em gestão de pessoas Fonte: Os autores

A distribuição revelada na figura 9 confirma que os respondentes que não atuam na área de gestão de pessoas trabalham, em sua maioria, na área administrativa, seguidas por profissionais de nível superior. Essas informações permitem constatar que o curso é abrangente e de importância em diversas áreas de atuação.

A seguir, está destacada a formação de nível superior dos entrevistados.

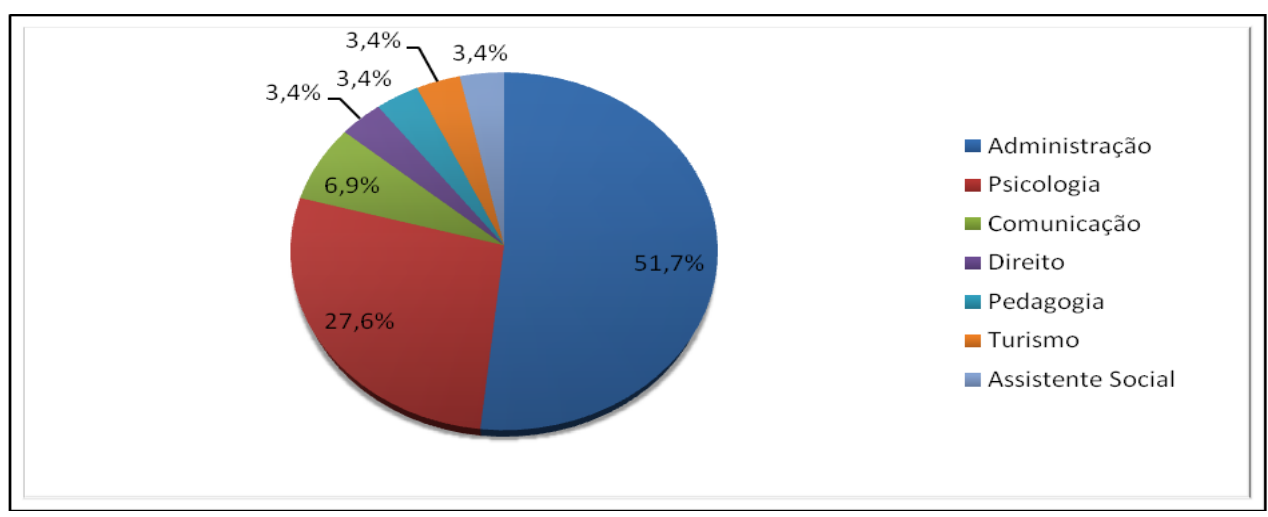

Figura 10 Formação superior dos alunos Fonte: Os autores

$\mathrm{Na}$ figura 10, é possível notar que o curso atrai principalmente graduados em Administração e Psicologia, o que não descarta o interesse de graduados em outras áreas.

A figura 11 demonstra por quanto tempo os alunos trabalham. 


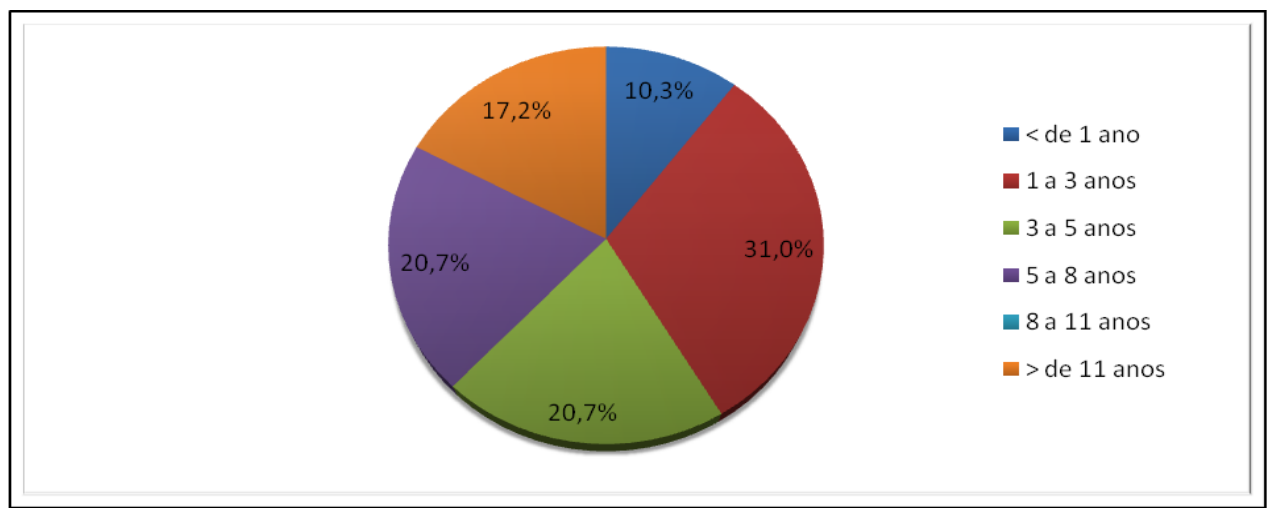

Figura 11 Tempo de trabalho

Fonte: Os autores

Percebe-se que a maior parte $(41,3 \%)$ dos respondentes iniciou sua carreira há menos de 3 anos. Esses dados podem revelar que os cursos de MBA ajudam a qualificar, principalmente no início da trajetória profissional. Trata-se de uma informação de grande relevância para o planejamento dos cursos e a condução das aulas, uma vez que o tipo de necessidades do público alvo é fortemente influenciado pelo nível de maturidade na carreira.

Em duas questões, foi solicitado aos respondentes que estabelecessem uma hierarquia de importância, sendo atribuído "1" para o fator mais importante, "2" para a segundo mais importante e assim sucessivamente. Não havia limites para as marcações, podendo o sujeito marcar apenas uma ou até todas as opções, desde que as hierarquizassem. A seguir, estão revelados os fatores motivadores da decisão de cursar um MBA.

Tabela 1 Motivo da decisão de cursar um MBA

\begin{tabular}{|c|c|c|c|c|c|c|}
\hline O que o motivou a cursar um MBA? & $\mathbf{1}^{\mathbf{0}}$ & $\mathbf{2}^{\mathbf{o}}$ & $3^{\circ}$ & $4^{\circ}$ & $\mathbf{5}^{\mathbf{0}}$ & $6^{\mathbf{0}}$ \\
\hline Exigência da empresa & & & 1 & & & \\
\hline Vontade de adquirir novos conhecimentos & 10 & 10 & 2 & & & \\
\hline Desejo de se capacitar melhor para as atividades profissionais & 14 & 6 & 1 & & & \\
\hline Obtenção de salário mais elevado & 1 & 4 & 1 & 2 & 2 & \\
\hline Desejo de mudar de emprego & 1 & 3 & 2 & 1 & & \\
\hline Conhecer novas pessoas e aumentar o network & & & 4 & 2 & & \\
\hline Ocupar tempo livre & & 1 & & & & \\
\hline Ser reconhecido como pós-graduado & 1 & 2 & 3 & 1 & & \\
\hline Agregar pontos em concursos públicos & 1 & 1 & & 2 & & 1 \\
\hline \multicolumn{7}{|l|}{ Pressão dos pais ou familiares } \\
\hline Capacitar melhor para atuar na área empresarial & 1 & & & & & \\
\hline
\end{tabular}

Fonte: Os autores

Para uma melhor visualização da importância atribuída a cada fator, procedeu-se a seguinte operação: multiplicou-se por 6 as marcações feitas, em cada fator, como sendo o $1^{\circ}$ 
em importância; por 5 as marcações como $2^{\circ}$ e assim sucessivamente, até as marcações em $6^{\circ}$, que foram consideradas como peso 1 . O total de pontos alcançados está revelado a seguir:

Tabela 2 Ponderação da importância dos motivos da decisão de cursar um MBA

\begin{tabular}{lc} 
Fator & Pontos \\
\hline Vontade de adquirir novos conhecimentos & 118 \\
Desejo de se capacitar melhor para as atividades profissionais & 118 \\
Obtenção de salário mais elevado & 40 \\
Desejo de mudar de emprego & 32 \\
Ser reconhecido como pós-graduado & 31 \\
Conhecer novas pessoas e aumentar o network & 22 \\
Agregar pontos em concursos públicos & 18 \\
Capacitar melhor para atuar na área empresarial & 6 \\
Ocupar tempo livre & 5 \\
Exigência da empresa & 4 \\
Pressão dos pais ou familiares & 0 \\
\hline
\end{tabular}

Fonte: Os autores

Conforme se percebe, "vontade de adquirir novos conhecimentos" e "desejo de capacitar melhor para as atividades profissionais" são os dois principais fatores que motivaram os alunos respondentes a buscarem por um curso de MBA. A busca de novos conhecimentos é inerente a qualquer forma de educação. A busca de capacitação para atividades profissionais decorre da necessidade imperiosa de qualificação para um mercado de trabalho cada vez mais exigente e competitivo, conforme anteriormente destacado.

Em seguida, aparece a busca de uma melhor remuneração. Os alunos que valorizaram esse fator são, provavelmente, aqueles que atuam em organizações que possuem planos de carreira e que concedem progressão funcional em função da maior titulação acadêmica.

O desejo de mudar de emprego pode revelar uma percepção de que a pós-graduação abre portas em cargos e organizações que exigem maior qualificação profissional. Considerando as características da sociedade contemporânea, parece natural a opção de fazer carreira em diferentes organizações.

Bem próximo a esse fator, está o desejo de ser reconhecido como pós-graduado, que revela uma percepção de status diferenciado associado aos cursos nesse nível.

Houve ainda marcações significativas na opção de pontuar em concursos públicos. Ainda que tal escolha tenha sido restrita a poucos respondentes, dos que a assinalaram, quase a metade a considerou como de grande relevância, atribuindo-lhe a $1^{\mathrm{a}}$ ou $2^{\mathrm{a}}$ opção.

Os demais fatores tiveram marcação muito pouco significativa. As opções relacionadas a ocupar o tempo livre, pressão dos pais ou exigência da empresa podem ter 
alcançado baixa marcação em função de não serem "politicamente corretas". Ou seja, talvez os estudantes não queiram assumir que motivos como esses, que não são propriamente "nobres" tenham influenciado sua decisão.

Interessante, porém, observar a baixa importância atribuída a capacitar-se melhor para atuar na área empresarial. Esperava-se que esse fator alcançasse maior impacto, uma vez que a qualificação profissional representa um objetivo básico de qualquer MBA.

Além dos fatores que determinaram a decisão de cursar uma pós-graduação, foram também levantados os motivos da escolha do MBA em Gestão Estratégica de Pessoas da UFJF, sendo encontrados os resultados a seguir demonstrados.

Tabela $3 \mathrm{O}$ que motivou o aluno a decidir pelo MBA em Gestão Estratégica de Pessoas na UFJF

\begin{tabular}{|c|c|c|c|c|c|}
\hline $\begin{array}{l}\text { Motivos por a cursar o MBA em Gestão Estratégica } \\
\text { de Pessoas na UFJF }\end{array}$ & $\mathbf{1}^{\mathbf{o}}$ & $2^{\mathbf{o}}$ & $3^{\mathbf{o}}$ & $4^{\circ}$ & $5^{\circ}$ \\
\hline Pela grade curricular & 9 & 10 & 1 & & \\
\hline Pela tradição/ nome da instituição & 12 & 9 & & 1 & \\
\hline Pelos professores & 1 & 1 & 2 & & \\
\hline Por indicação dos amigos & 4 & 1 & 2 & 1 & \\
\hline Pela localização & 1 & 2 & 1 & & 1 \\
\hline Pelo preço & & 1 & & & \\
\hline Por trabalhar na área & 2 & & & & \\
\hline
\end{tabular}

Fonte: os autores

Aplicando-se o mesmo procedimento de ponderação da importância de cada fator utilizado na questão anterior, obtêm-se os seguintes resultados:

Tabela 4 Ponderação da importância dos motivos da decisão de cursar um MBA

\begin{tabular}{lc} 
Fator & Pontos \\
\hline Pela tradição/ nome da instituição & 98 \\
Pela grade curricular & 88 \\
Por indicação dos amigos & 32 \\
Pela localização & 17 \\
Pelos professores & 15 \\
Outros: Por trabalhar na área & 10 \\
Pelo preço & 4 \\
\hline
\end{tabular}

Fonte: Os autores

$\mathrm{Na}$ tabela 2, é possível visualizar os dois principais fatores que contribuíram para a escolha dos alunos pelo MBA em Gestão Estratégica de Pessoas na UFJF. Esses fatores são: tradição (nome da instituição) e a grade curricular do curso. 
A Universidade Federal de Juiz de Fora possui 28 cursos de graduação entre os melhores do país, de acordo com o Guia do Estudante, publicado pela Editora Abril, o qual é baseado nas avaliações realizadas pelo Exame Nacional de Desempenho de Estudantes (ENADE). A UFJF está entre as vinte melhores instituições de ensino superior de acordo com a última divulgação do Índice Geral dos Cursos (IGC) do Ministério da Educação (MEC). Além disso, uma organização espanhola, a Scimago Institutions Ranking (SIR), classificou a UFJF em $70^{\circ}$ entre 1.254 instituições de ensino superior da América Latina. Todas essas classificações e índices, além da história, justificam o prestígio e a tradição que hoje é valorizada pelos alunos na busca de um curso de graduação e pós-graduação (UFJF, 2012).

Os resultados apresentados também demonstram que os alunos, em sua maioria, não estão preocupados apenas em obter o diploma de pós-graduado, e sim em ter uma educação consistente e que possa agregar conhecimento à vida profissional e pessoal. A busca em conhecer mais o curso é notável quando o respondente identifica a indicação dos amigos e o reconhecimento dos professores como fatores motivacionais pela escolha do curso.

Outro fator importante é a localização, que aparece como o $4^{\circ}$ lugar, possivelmente, pelo fato que alguns estudantes não são da cidade de Juiz de Fora, e a UFJF é a instituição mais próxima de suas residências que possui programa de MBA reconhecido.

Além das questões fechadas, foram incluídas outras duas perguntas abertas. Estas tiveram o objetivo de captar comentários dos alunos que pudessem contribuir para uma compreensão melhor do que foi marcado nas perguntas anteriores e também incluir aspectos não contemplados nas mesmas. Apenas uma pessoa não respondeu essas duas questões, dez responderam apenas a primeira questão e dezoito responderam as duas questões.

A primeira questão tinha como objetivo investigar quais são as perspectivas do aluno em âmbito profissional após concluir o curso de MBA. A maioria dos respondentes deseja adquirir conhecimentos de gestão e técnicas, além de aumentar as oportunidade de emprego e possivelmente auferir maiores ganhos salariais. Como exemplos, podem ser mencionados os seguintes comentários: "Minhas perspectivas são um aumento significativo nas alternativas de emprego, bem como a aquisição do conhecimento técnico mais aprofundado sobre a gestão administrativa de pessoas" e "quero me tornar uma profissional mais qualificada e versátil, capaz de desenvolver atividades no domínio da gestão de pessoas, ou seja, uma profissional preparada para competir no mercado de trabalho". 


\section{FATORES DE INFLUÊNCIA NA ESCOLHA DE UM CURSO DE PÓS-GRADUAÇÃO: UMA ANÁLISE DO \\ MBA EM GESTÃO ESTRATÉGICA DE PESSOAS DA UFJF \\ DOI: http://dx.doi.org/10.5007/1983-4535.2014v7n2p86}

As respostas dadas à questão apresentada anteriormente reflete o que foi demonstrado nas figuras 6,8 e 11 . Os respondentes são, em sua maioria, profissionais que se encontram no nível de analista, possuem ainda pouca experiência profissional e são jovens. Ou seja, esse perfil de estudante procura formação técnica e almeja novas oportunidades de emprego e deseja, provavelmente, ser reconhecido através de promoções ou ascensão hierárquica na organização onde atuam.

A segunda questão teve o seguinte enunciado: "Faça comentários que possam auxiliar na compreensão de seu posicionamento". Algumas das pessoas que responderam esta questão complementaram sobre os motivos que o fizeram escolher o curso, como por exemplo: "reconhecimento profissional, satisfação pessoal, ganhos materiais (salários/ benefícios)".

Outras comentaram sobre o que esperavam e o que obtiveram com o curso e outras ainda sobre o que representa a busca por conhecimento. Como exemplos de comentários podem ser citados: "É inegável o crescimento profissional que adquirimos com a educação continuada. A cada dia me sinto mais preparada e mais segura para os desafios do mercado. Hoje temos um novo cenário imposto pelo mercado de trabalho, que valoriza multiconteúdos e multiespecialistas, e investir na capacitação é, sem dúvida, a melhor opção para quem busca estabilidade e valorização profissional. Eu estou buscado exatamente isto". E também: "Não somos completos, estamos sempre em formação".

\section{CONSIDERAÇÕES FINAIS}

Conforme destacado, a pesquisa cujos resultados estão aqui apresentados procurou investigar os fatores que levaram os alunos do MBA em Gestão de Pessoas da UFJF a escolherem o curso. Partiu-se do pressuposto de que é importante para a instituição promotora de um curso desse tipo, conhecer bem o público-alvo que tem sido por ela atendido. De posse desse conhecimento, é possível consolidar o posicionamento no mercado educacional e garantir um melhor atendimento das necessidades e expectativas dos alunos. Em um ambiente marcado por crescente competição, é fundamental esse tipo de informação.

Verificou-se que as organizações na atualidade estão procurando profissionais mais qualificados, assim como o próprio profissional está à procura de se qualificar cada vez mais. Essa característica deriva da própria natureza da sociedade contemporânea, na qual o principal recurso produtivo passou a ser o conhecimento acumulado em cada organização. Essa percepção, encontrada em muitos dos autores consultados, confirmou-se pelos dados obtidos 


\section{FATORES DE INFLUÊNCIA NA ESCOLHA DE UM CURSO DE PÓS-GRADUAÇÃO: UMA ANÁLISE DO \\ MBA EM GESTÃO ESTRATÉGICA DE PESSOAS DA UFJF \\ DOI: http://dx.doi.org/10.5007/1983-4535.2014v7n2p86}

nos questionários aplicados, na medida em que os respondentes atribuíram uma elevada importância ao objetivo de adquirir e aprofundar conhecimentos.

Outro motivo de destaque nas respostas dos alunos foi a vontade de adquirir novos conhecimentos e desejo de capacitar melhor para as atividades profissionais. Essas características evidenciam a importância atribuída ao aprimoramento de conhecimentos técnicos e desenvolvimento de habilidades cognitivas. Mais do que simplesmente obter um certificado, nota-se uma expectativa clara de aumentar as competências profissionais possuídas. Se o mercado atual é marcado por grande competitividade entre as empresas, também o mercado de trabalho exige preparo diferenciado para que cada pessoa mantenha sua empregabilidade, ou seja, sua condição de obter um bom emprego.

É perceptível que os alunos participantes da pesquisa procuraram informações antes da escolha do curso, e essas informações adquiridas se tornaram fonte de motivação para a realização do mesmo. Foram consideradas como principais fontes de motivação a tradição/nome da instituição e a grade curricular. Portanto, os alunos que procuram o MBA em foco preocuparam-se em pesquisar e escolher um curso que tenha prestígio e aceitação na sociedade. A despeito de, como já destacado, a obtenção do certificado não ser a principal necessidade buscada, titular-se por uma instituição com reconhecida credibilidade é um fator que pesa na escolha. Não somente as notícias veiculadas na imprensa e os rankings de qualidade depõem a favor da UFJF. Conforme verificado, o testemunho de colegas que estudaram na instituição tem sido um fator importante na escolha do curso.

Além disso, pelo perfil dos respondentes pode-se destacar que a maioria está em início da carreira profissional e possui baixa ou média experiência de trabalho, o que, consequentemente, pode ser fator primordial para que esses busquem uma qualificação melhor para que possam almejar uma ascensão profissional ou sentissem mais qualificados para realizarem sua profissão.

Também chama a atenção o fato de que muitos não trabalham em área responsável pela gestão de pessoas. O curso parece atrair profissionais das mais diversas áreas que desejam preparar-se melhor para exercer cargos de gestão. É interessante, portanto, que sejam contempladas competências relacionadas à liderança nas diversas disciplinas que compõem a grade curricular. Outros ainda parecem almejar um curso de pós-graduação em qualquer área administrativa e escolhem gestão de pessoas por ser uma área menos árida do que outras que 
envolvem aspectos técnicos mais quantitativos. Isso pode se manifestar especialmente naqueles que são graduados na área de ciências humanas e sociais.

Ficou constatado também que a educação é algo contínuo e deve ser sempre aprimorado e atualizado, refletindo a complexidade, a singularidade e o dinamismo do ambiente e das organizações. Em decorrência, espera-se que os gestores da Faculdade de Administração e Ciência Contábeis, que promove o curso estudado, busquem constantemente ampliar o conhecimento das necessidades e expectativas de seus alunos, bem como do mercado de trabalho, para que o curso continue a ser bem procurado e alcance avaliação positiva por parte do seu principal público interessado: os alunos.

O presente artigo pode vir a ser fonte de motivação para que alunos ou pesquisadores venham a estudar sobre os outros cursos de MBA ofertados pela universidade estudada, ficando assim, como sugestão para futuras pesquisas.

\section{REFERÊNCIAS}

AAKER, D. A.; KUMAR, V.; DAY, G. S. Pesquisa de marketing. São Paulo: Atlas, 2004.

ANDRADE, Daniel Pereira. Empresa humana ou humano empresa? Gv executivo: São Paulo, vol.10, n.1, PP. 38-41, jan-jun/2011.

BARBOZA, N. MBA: Diferencial na carreira e no currículo. Disponível em: http://www.guiamba.com.br/mba-diferencial-na-carreira-e-no-curriculo/. Acesso em 02/10/2012.

Bardin, Laurence. Análise de conteúdo. Lisboa: Edições 70, 2000.

BERTUCCI, J. L. O. Metodologia básica para elaboração de trabalhos de conclusão de cursos (TCC): ênfase na elaboração de TCC de pós-graduação Lato Sensu. São Paulo: Atlas, 2009.

BRUNO, L. Educação, qualificação e desenvolvimento econômico. In L.Bruno (Org.), Educação e trabalho no capitalismo contemporâneo: leituras selecionadas (pp. 91-123). São Paulo: Atlas, 1996.

CAREGNATO, R.C.; MUTTI, R. Pesquisa qualitativa: análise de discurso versus análise de conteúdo. Texto Contexto Enfermagem. Florianópolis, 2006 Out-Dez; 15(4): 679-684.

CASTRO, C. M. O ensino da administração e seus dilemas: Notas para debates. Revista de Administração de Empresas, v. 21, n. 3, p. 58-61, 1981.

CERVO, Amado L.; BERVIAN, Pedro A.; DA SILVA, Roberto. Metodologia científica. São Paulo. Pearson Prentice Hall, 2007. 
CHURCHILL, Gilbert A. Jr.; PETRER, J. Paul. Marketing: Criando valor para o cliente. $2^{\mathrm{a}}$ Ed. São Paulo: Saraiva, 2005.

COSTA, Giovani Gláucio de Oliveira. Curso de estatística básica: teoria e prática. São Paulo: Atlas, 2011.

DOWBOR, L. Educação, tecnologia e desenvolvimento. In L. Bruno (Org.), Educação e trabalho no capitalismo contemporâneo: leituras selecionadas (pp.17-40). São Paulo: Atlas, 1996.

FLEURY, Maria Tereza Leme; FISHER, Rosa Maria. Cultura e Poder nas Organizações. 2 ed. São Paulo: Atlas S.A., 1996.

FOGAÇA, A.. A educação e reestruturação produtiva. In FOGAÇA, A. (Org.) Políticas de emprego no Brasil (pp. 30-45). Campinas: Instituto de Economia Unicamp, 1998.

GASKELL, G. Entrevistas individuais e grupais. In: Pesquisa qualitativa com texto, imagem e som - um manual prático. 3 ed. Petrópolis: Vozes, 2004.

GIL, Antônio Carlos. Como elaborar projetos de pesquisa. São Paulo: Atlas, 2009.

GÍLIO, I. Trabalho e educação: formação profissional e mercado de trabalho. São Paulo: Nobel, 2000.

GONDIM, S. M. G. Perfil profissional e mercado de trabalho: relação com formação acadêmica pela perspectiva de estudantes universitários. Estud. psicol.

(Natal) vol.7 no.2 Natal July/Dec. 2002.(http://dx.doi.org/10.1590/S1413-

294X2002000200011) acessado em 15/10/2012.

HAWKINS, D.; MOTHERSBAUGH, D.; BEST, R. Comportamento do consumidor: construindo a estratégia de marketing. Rio de janeiro: Campus, 2007.

KARLOF, B. Conceitos básicos de administração: um guia conciso. Rio de Janeiro: Rocco, 1999.

KOTLER, Philip. Administração de Marketing: analise, planejamento, implementação e controle. São Paulo: Atlas S.A., 1998.

Administração de marketing: análise, planejamento, implementação e controle. 5. ed. São Paulo: Atlas, 2001.

Marketing para o século XXI: como criar, conquistar e dominar mercados. São Paulo: Ediouro, 2009.

MARTINS, C. B. Surgimento e expansão dos cursos de Administração no Brasil (19521983). Ciência e Cultura, v. 41, n. 7, p. 663-676, 1989. 
MEDEIROS, Janine Fleith de; CRUZ, Cassiana M. L. Comportamento do Consumidor: fatores que influenciam no processo de decisão de compra dos consumidores. Teoria e Evidencia Econômica, Edição Especial, v. 14, p.167-190, 2006.

MINTZBERG, Henry; AHLSTRAND, Bruce \& LAMPEL, Joseph. Safári de estratégia: um roteiro pela selva do planejamento. PortoAlegre: Bookman, 2000.

MOTTA, Fernando; VASCONCELOS, Isabela. Teoria geral da administração. $3^{\text {a }}$ Edição. São Paulo: Thomson, 2006.

MOWEN, J.C.; MINOR, M.S. Comportamento do consumidor. Tradução: Vera Jordan. São Paulo: Prentice Hall, 2003.

OLIVEIRA, Ramon de (2001a). A Teoria do Capital Humano e a Educação Profissional Brasileira. Rio de Janeiro: Boletim Técnico do SENAC. Volume 27. no. 1. Janeiro/Abril.

SANTOS, C. M. Tradições e contradições da pós-graduaçãono Brasil. Educação e Sociedade. Campinas, v.24, n. 83, p. 627-641, ago.2003.

SCHAFFER, Augusto F. Caetano. O MBA brasileiro na gestão de recursos humanos. 2010. Dissertação (Mestrado em Administração Pública). Fundação Getulio Vargas, Rio de Janeiro.

SHETH, J. N.; MITTAL, B.; NEWMAN, B. I. Comportamento do cliente: indo além do comportamento do consumidor. São Paulo: Atlas, 2001.

SOLOMON, Michael R. Comportamento do Consumidor: comprando, possuindo e sendo. Porto Alegre: Bookman, 2002.

SLATER, D. Cultura do consumo \& modernidade. São Paulo: Nobel, 2002.

UFJF. UFJF tem 28 cursos entre os melhores do país conforme Guia do Estudante Disponível em: http://www.ufjf.br/secom/2012/09/05/ufjf-tem-28-cursos-entre-os-melhoresdo-pais-conforme-guia-do-estudante/. Acesso em: 09/11/2012.

VERGARA, Silvya Constant. Projetos e relatório de pesquisa em administração. 6. ed. São Paulo: Atlas, 2005.

VERHINE, R. Pós-Graduação no Brasil e nos Estados Unidos: uma análise comparativa. Educação, Porto Alegre, v.31, n.2, p. 166-172, maio/ago. 2008.

Métodos para coleta de dados no campo. São Paulo: Editora Atlas, 2010.

WARDE, I. Fascinantes business schools. Le Monde Diplomatique, v. 1, n.3, maio, 2000. (http://www.diplo.gov.br/). Acessado em 23/07/2012.

YIN, Robert. Estudo de caso: planejamento e métodos. Porto Alegre: Bookman, 2010. 